\title{
PERAN AKUNTANSI DAN PEMASARAN DALAM MEMBANGUN KOPERASI SEKOLAH UNTUK MENINGKATKANKESEJAHTERAAN ANGGOTA KOPERASI SERTA MENUMBUHKAN ENTREPRENUER DI ERA MILENIAL
}

\author{
Rifani Akbar Sulbahri'1), Yuni Rachmawati ${ }^{2)}$, Melia Frastuti $^{3)}$ \\ Yuni Adinda Putri ${ }^{4)}$, Firmansyah Arifin ${ }^{5)}$ \\ 1)233)4)5)Fakultas Ekonomi Universitas Tridinanti \\ Jl. Kapten Marzuki No.2246, Palembang \\ Email : rifaniakbar.sulbahrimadjir@gmail.com ${ }^{1)}$, yunirachmawatise@yahoo.com²), melia frastuti@univ- \\ tridinanti.ac.id ${ }^{3)}$, yuniadindaputri94@gmail.com ${ }^{4}$ ), Firmansyah.arifin@ymail.com $^{5)}$
}

\begin{abstract}
ABSTRAK
Dalam upaya untuk menumbuhkan entrepreneur, edukasi ekonomi dan meningkatkan kesejahteraan anggota koperasi, siswa serta masyarakat sekitar melalui pendidikan non formal yaitu penambahan ilmu dan keterampilan dalam memanfaatnya potensi siswa, guru, pihak sekolah Tim Pengabdian mengadakan kegiatan penyuluhan di sekolah, masalah utama dari sekolah yaitu belum adanya koperasi sekolah serta belum adanya minimarket di lingkungan sekitar sehingga pihak yayasan sedang mengusulkan pendirian koperasi sekolah di lingkungan SMA Taruna Bangsa Palembang. Tujuan penelitian ini adalah untuk memberikan pemahaman akan pentingnya membangun koperasi sekolah untuk meningkatkan kesejahteraan anggota serta menumbuhkan jiwa entrepreneur. Kegiatan ini juga mengedukasi bagaimana akuntansi dan pemasaran dalam membentuk dan mengelola koperasi sekolah mulai dari memasarkan produk koperasi, hingga menyajikan laporan keuangan koperasi. Metode penelitian adalah dengan menggunakan sistem workshop, yaitu penyajian materi secara lugas dilanjutkan dengan sistem interaksi tanya jawab antara peserta dan narasumber. Para peserta khususnya kepala sekolah dan pengelola telah memahami manfaat dan peran koperasi, bagaimana memasarkan produk koperasi serta bagaimana pencatatan keuangan koperasi sesuai standar. Diharapkan SMA Taruna Bangsa Palembang bisa mendirikan koperasi di sekolah yang akhirnya dapat menghidupkan perekonomian sekolah dan masyarakat lingkungan sekitar.
\end{abstract}

Kata kunci : Koperasi, Peranan Akuntansi, Peranan Pemasaran, Entrepreneur

\section{PENDAHULUAN}

SMA Taruna Bangsa adalah SMA swasta yang beroperasi dalam dunia Pendidikan di kota Palembang, yang dikenal dengan nama SMA taruna Bangsa, yang membedakan SMA tersebut dari SMA pada umumnya adalah kedisiplinan tinggi serta mendepankan norma-norma sosial yang dibungkus dengan semi militer, SMA Taruna Bangsa yang memiliki jumlah siswa yang cukup banyak, yang menjadi salah satu SMA Swasta favorit di kota Palembang, memiliki lokasi yang cukup strategis di tengah kota, yang menjadikan SMA Taruna Bangsa Mudah dikenal bagi kalangan masyarakat, Serta di daerah tersebut masyarakat tidak memiliki akses yang dekat untuk membeli kebutuhan pokok karena belum ada minimarket di daerah tersebut. Dari hasil pengamatan SMA Taruna Bangsa hanya memiliki kosentrasi IPA (Ilmu Pengetahuan Alam) sehingga dirasa perlu pembekalan juga mengenai Ilmu Pendidikan Sosial (IPS) yang salah satu kosentrasi ilmunya adalah Ekonomi.

Ekonomi adalah salah satu isu global yang tidak dapat dipisahkan dari kehidupan sosial, maka ekonomi menjadi salah satu isu yang sangat penting yang harus dipahami. SMA Taruna Bangsa yang telah membuka 2 waktu dalam melakukan kegiatan sekolah yaitu pagi dan siang dianggap masyarakat sebagai satu wadah edukasi yang sangat diminati masyarakat sehingga perlu adanya pengetahuan tentang ekonomi agar siswa, jajaran guru dan yayasan dapat mengedukasi masyarakat sekitar. Dalam operasionalnya SMA Taruna Bangsa Belum memiliki Koperasi sekolah yang dapat menjadi wadah membangun enterpreneur dan kesejahteraan anggota koperasi dan Sekolah.

Berdasarkan Undang-Undang Dasar 1945 dalam tata prekonomian nasional yang disusun sebagai 
usaha Bersama atas asas kekeluargaan dan demokrasi ekonomi Koperasi sebagai gerakan ekonomi rakyat maupun sebagai badan usaha berperan serta untuk mewujudkan masyarakat yang maju, adil dan makmur. Landasan dasar dalam koperasi Indonesia berakar pada UUD 1945 pasal 33 ayat (1) yang berisi cita-cita untuk mengembangkan ekonomi yang berasaskan kekeluargaan. Selanjutnya UU Nomor 25 Tahun 1992 memberikan pedoman bagi pemerintah dan masyarakat tentang cara-cara untuk menjalankan koperasi, termasuk koperasi sekolah unincorporated koperasi.

Administrator koperasi sekolah dilakukan oleh siswa di bawah bimbingan kepala sekolah dan guru. Dari hasil kunjungan ke SMA Taruna Bangsa diperoleh informasi bahwa sekolah tersebut belum memiliki koperasi dan pengelola sekolah sebenarnya telah memiliki keinginan untuk membentuk sebuah koperasi namun belum terbentuk karena keterbatasan dalam tata cara pembentukan serta pengelolaan keuangan koperasi yang baik. Berdasarkan permasalahan tersebut dosen Fakultas Ekonomi Universitas Tridinanti Palembang berminat untuk melakukan pengabdian masyarakat dengan memberikan penyuluhan tentang Peran Akuntansi dan Pemasaran dalam membangun koperasi sekolah untuk meningkatkan sejehateraan anggota koperasi serta menumbuhkan entrepreneur bagi siswa,guru,angota koperasi, dan Yayayasan sekolah dan pelatihan ini yang nantinya dapat mengembangkan potensi perekonomian di lingkungan sekolah tersebut. Berdasarkan UndangUndang Dasar 1945 pengabdian masyarakat ini menjadi tujuan membangun koperasi sekolah bagi sekolah yang belum memiliki koperasi.

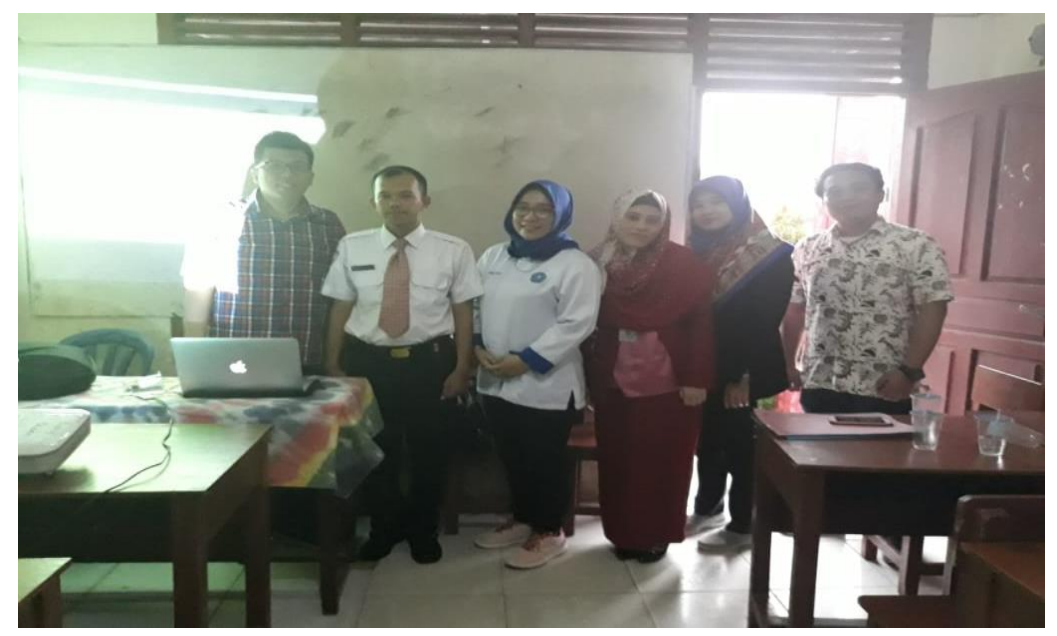

Gambar 1. Foto bersama tim PKM dan Kepala Sekolah SMA Taruna Bangsa Palembang

\subsection{Tujuan}

Pengabdian Kepada Masyarakat ini bertujuan memberikan pemahaman akan pentingnya membangun koperasi sekolah untuk meningkatkan kesejahteraan anggota serta menumbuhkan jiwa entrepreneur. PKM ini juga mengedukasi bagaimana akuntansi dan pemasaran dalam membentuk dan mengelola koperasi sekolah mulai dari memasarkan produk koperasi, hingga menyajikan laporan keuangan koperasi.

\subsection{Manfaat Kegiatan}

Kegiatan PKM ini memberikan pemahaman lebih dalam mengenai koperasi, akuntansi, pemasaran dan enterpreneursip kepada pengurus SMA Taruna Bangsa, sehingga diharapkan wacana pendirian koperasi di SMA ini dapat segera direalisasikan. Pengetahuan mengenai pemasaran yang telah disampaikan sehingga bekal untuk memasarkan produk koperasi agar dapat lebih dikenal dan menambah anggota, yang berimplikasi pada penambahan modal koperasi sehingga koperasi dapat lebih berkembang lagi. Begitupula dengan ilmu akuntansi, diharapkan pengelola koperasi dapat melakukan pengakuan pendapatan dan beban sesuai dengan standar akuntansi keuangan untuk kopersasi yaitu SAK ETAP. Pengakuan pendapatan dan beban yang tepat akan menampilkan kinerja koperasi secara tepat pula. Sisa hasil usaha, posisi harta dan hutang dapat dibaca oleh user sehingga dapat menggunakan laporan keuangan koperasi untuk penggambilan keputusan guna pengembangan koperasi dan kesejahteraan anggota koperasi. 


\section{METODE PELAKSANAAN PENGABDIAN}

Kegiatan Pengabdian Kepada Masyarakat yang dilaksanakan pada SMA Taruna Bangsa adalah sebagai berikut :

Tabel 1. Susunan Acara Pengabdian Kepada Masyarakat

\begin{tabular}{|c|c|c|c|}
\hline $\begin{array}{c}18 \\
\text { Des } \\
2018\end{array}$ & Waktu & Materi & Penyaji \\
\hline & $\begin{array}{r}09.00-09.15 \\
09.15-10.45 \\
10.45-12.00\end{array}$ & $\begin{array}{ll}- & \text { Pembukaan } \\
\text { - } & \text { Kata sambutan dari Kepala } \\
& \text { Sekolah SMA Taruna Bangsa } \\
\text { - } & \text { Kata sambutan dari ketua Tim } \\
& \text { Pengabdian } \\
\text { - } \quad \text { Penyampaian Materi } 1 \\
\text { Koperasi } \\
\text { - Penyampaian Materi } 2 \\
\text { Peranan Akuntansi } \\
-\quad \text { Penyampaian Materi } 3 \\
\text { Standar Akuntansi }\end{array}$ & $\begin{array}{l}\text { TIM Pengabdian } \\
\text { Muadin, S.Pd, M.Pd } \\
\text { Firmansyah Arifin, SE, MM, Ak, } \\
\text { CA } \\
\text { Firmansyah Arifin, SE, MM, Ak, } \\
\text { CA } \\
\text { Melia Frastuti, SE. M.Ak } \\
\text { Yuni Rachmawati, SE, M.Si, Ak, } \\
\text { CA }\end{array}$ \\
\hline & $\begin{array}{l}12.00-13.00 \\
13.00-14.00 \\
14.00-15.00\end{array}$ & $\begin{array}{l}\text { ISHOMA } \\
\text { - Penyampaian Materi } 4 \\
\text { Entrepreneurship } \\
\text { Penyampaian Materi } 5 \\
\text { Pemasaran Koperasi }\end{array}$ & $\begin{array}{l}\text { Tim dan Peserta } \\
\text { Rifani Akbar Sulbahri, SE, MM, } \\
\text { M.Ak, Ak, CA } \\
\text { Yuni Adinda Putri, SE, M.Si }\end{array}$ \\
\hline & $\begin{array}{l}15.00-16.00 \\
16.00-17.00\end{array}$ & $\begin{array}{ll}\text { - } & \text { Tanya Jawab/ diskusi } \\
\text { - } & \text { Ramah-tamah dan foto-foto }\end{array}$ & $\begin{array}{l}\text { TIM dan Peserta } \\
\text { TIM dan Peserta }\end{array}$ \\
\hline
\end{tabular}
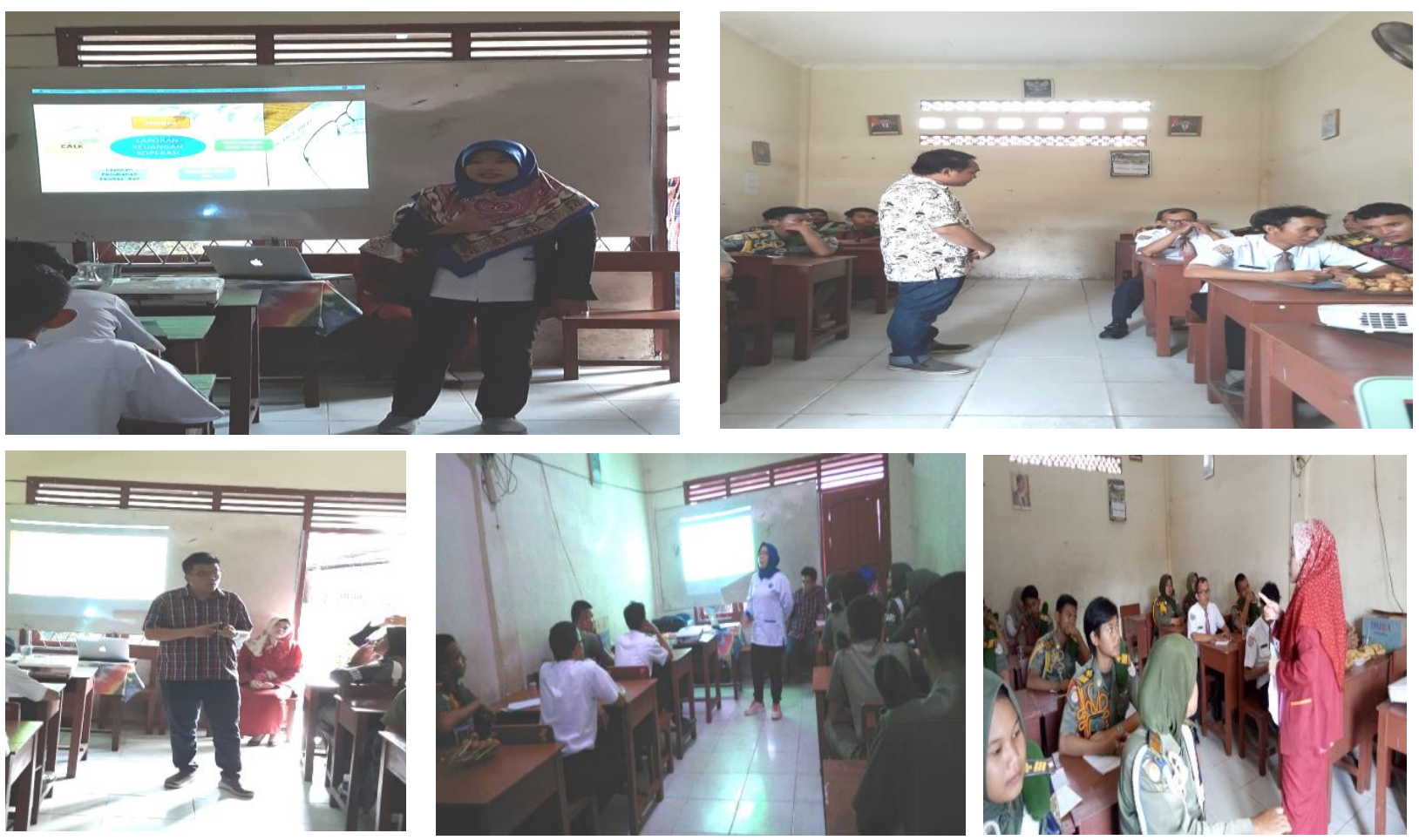

Gambar 2. Penyampaian Materi Oleh Tim Pengabdian 


\section{HASIL DAN PEMBAHASAN}

Pengabdian Kepada Masyarakat (PKM) yang kami laksanakan di SMA Taruna Bangsa pada hari Selasa, 18 Desember 2018 disambut sangat baik oleh kepala sekolah, pegawai dan para siswa. Kegiatan pengabdian dibuka dengan kata sambutan dari kepala sekolah SMA Taruna Bangsa yaitu oleh Bpk Muadin, S.Pd, M.Pd. dilanjutkan kata sambutan dari ketua tim pengabdian yaitu Bpk Firmansyah Arifin, SE., MM., Ak., CA dan perkenalan anggota tim lainnya. Kami 5 orang anggota pengabdian, masing-masing menyampaikan materi yang berbeda dimulai dari pengenalan apa itu koperasi hingga bagaimana memasarkan produk dan mencatat transaksi akuntansinya.

Materi disampaikan secara sistematis agar peserta bisa mengikuti dan paham. Pertama, para peserta yang merupakan siswa IPA digiring pemahamannya dengan penyampaian ringan mengenai pengenalan koperasi dan manfaatnya oleh ketua tim. Antusias peserta sudah terlihat dari beberaapa pertanyaan yang dilontarkan kepada pemateri. Selanjutnya materi kedua mengenai peran akuntansi dalam koperasi disampaikan oleh Ibu Melia Frastuti, SE, M.Ak. Pemateri ketiga disampaikan oleh Ibu Yuni Rachmawati, SE, M.Si, Ak, CA mengenai standar dan perlakuan akuntansi suatu koperasi. Tidak terasa waktu telah nenunjukkan Pk.12.00 WIB, sehingga pemaparan dijedah dengan istirahat, sholat zhuhur dan makan siang bersama. Pengabdian kepada masyrakat dilanjutkan kembali pada pukul 13.00 WIB. Pemateri ke empat yaitu Rifani Akbar Sulbahri, SE, MM, M.Ak, Ak, CA memaparkan tentang entrepreneurship dan dilanjutkan oleh Yuni Adinda Putri,SE, M.Si mengenai pemasaran koperasi.

Meskipun bukan berlatar belakang IPS, Alhamdulilah para peserta sangat antusias hingga semua materi dapat selesai disampaikan oleh kelima pemateri. Sejumlah pertanyaanpun diajukan oleh peserta termasuk kepala sekolah dan pengelola sekolah seperti mengenai tahapan yang harus dipenuhi untuk dapat mendirikan koperasi di SMA Taruna Bangsa ini dan bagaimana pencatatannya.

SMA Taruna belum memiliki koperasi di sekolah ini, namun ada wacana untuk mendirikan koperasi. Setelah mengikuti PKM, para peserta khususnya kepala sekolah dan pengelola mengetahui manfaat dan peran koperasi, bagaimana memasarkan produk koperasi serta bagaimana pencatatan keuangan koperasi sesuai standar. diharapkan SMA Taruna Bangsa Palembang semakin mantab dalam mendirikan koperasi di sekolah dan mampu menghidupkan perekonomian sekolah dan masyarakat lingkungan sekolah.

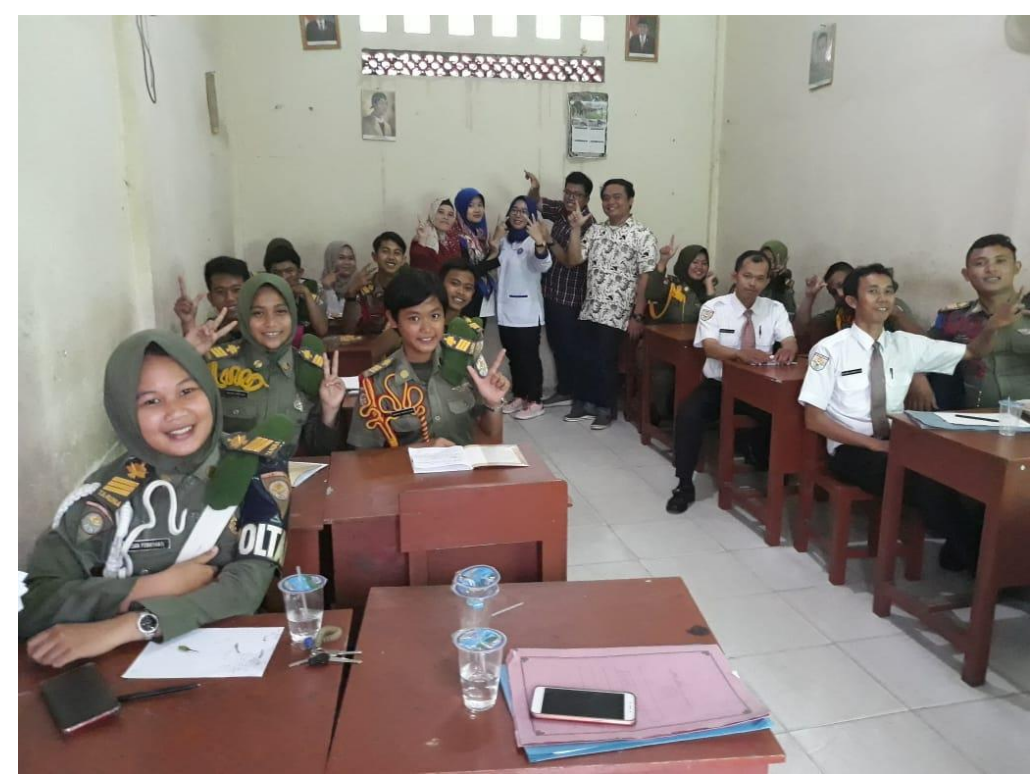

Gambar 3. Foto bersama Tim PKM dan peserta setelah penyampaian materi selesai

\section{KESIMPULAN}

Berdasarkan hasil pelaksanaan kegiatan yang telah dilakukan, dapat ditarik beberapa simpulan sebagai berikut;

1. Koperasi sangat dibutuhkan dilingkungan sekolah, baik bagi siswa maupun bagi sekolah itu sendiri dan masyarakat sekitar. 
2. Laporan keuagan koperasi disajikan berdasarkan Standar Akuntansi Keuangan Entitas Tanpa Akuntabilitas Publik.

3. Penyampaian materi tentang pengakuan pendapatan dan beban perusahan konstruksi kepada peserta pelatihan dapat meningkatkan pengetahuan sekaligus sebagai stimulan agar karyawan dan manajemen dapat menyajikan laporan keuangan secara mandiri.

\section{UCAPAN TERIMA KASIH}

Ucapan terimakasih penulis sampaikan kepada :

1. Yayasan Pendidikan Nasional Tridinanti Palembang

2. Rektor Universitas Tridinanti Palembang, Ibu, DR.Ir.Hj.Manisah,MP. beserta staf.

3. Dekan Fakultas Ekonomi Tridinanti Palembang, Bpk Syaiful Sahri,SE,MSi

4. Kepala Sekolah SMA Taruna Bangsa Palembang, Bpk.Muadin, SPd, M.Pd

\section{DAFTAR PUSTAKA}

Azaria, Vina Mukti. 2013. Penerapan Akuntansi Pada UMKM Unggulan di Kabupaten Kota Blitar dan Kesesuaiannya dengan SAK ETAP. Skripsi. Jember : Universitas Jember.

Cantillon, Richard. 1755 Essai Sur La Nature Du Commerce en General, London: Gyles.

Hannah Orwa Bula. 2012. "Evolution and Theories of Entrepreneurship: A Critical Review on the Kenyan Perspective", International Journal of Business and Commerce, Vol. 1, No.11, Lahore.

Hall. International editions. New Yersey. Fourth editions.

Hanel, ALferd. 1989. Basic Aspect of Cooperative Organization and Policies for Their Promotion in Developing Countries, Marburg.

Ikatan Akuntan Indonesia. 2009. Standar Akuntansi Keuangan per 1 Juli 2009. Jakarta : Salemba Empat. Ikatan Akuntan Indonesia. 2009. Standar Akuntansi Keuangan Entitas Tanpa Akuntabilitas Publik. Jakarta: Dewan Standar Akuntansi Keuangan IAI.

Jurnal Pengabdian Untuk Mu Negeri, Vol. 2 No. 2, November 2018 ISSN : 2550-0198. 138.

Kasmir. 2013. Kewirausahaan-Edisi Revisi, Jakarta: PT Rajagrafindo Persada.

Kieso , dan Terry. 2014. Intermediate Accounting : IFRS Edition. Edisi 2. John Wiley \& Sons.

Kottler, Phillip. 1980. Marketing Managemen. Analysis, Planning, and Control, Prentice.

Martani, Dwi,dkk. 2016. Akuntansi Keuangan Menengah Berbasis PSAK. Jakarta: Salemba Empat.

Nurdita, Raflesia. 2012. Analisis Penerapan Standar Akuntansi Keuangan Entitas Tanpa Akuntabilitas Publik (SAK ETAP) pada Koperasi yang ada di Kota Dumai. Skripsi. Pekanbaru : Universitas Riau.

Priambodo. 2006. Koperasi Sekolah: Titik Masuk Menguasai "Lingkaran Setan" Pengangguran dan Kewirausahaan. Jurnal Infokop. No.28 Tahun XXII. 2006 Jakarta: Dekopin.

Rudiantoro dan Siregar. 2012. Kualitas Laporan Keuangan UMKM Serta Prospek Implementasi SAK ETAP. Banda Aceh : Jurnal Akuntansi dan Keuangan Indonesia.

Soemarso, 2004. Akuntansi Suatu Pengantar, Edisi 5. Jakarta : Salemba Empat.

Sunyoto, Danang. 2013. Kewirausahaan Untuk Kesehatan. Yogyakarta: Nuha Medika.

Suryana. 2013. Kewirausahaan Pedoman Praktis: Kiat dan Proses Menuju Sukses. Edisi Ketiga, Jakarta: Penerbit Salemba.

Tim Penyusun IAI Sumsel. 2014. Pengantar Akuntansi. Edisi Revisi Kedua. Palembang : IAI Wilayah Sumsel.

Winardi.1980. Asas-asas Marketing, Bandung: Penerbit Alumni. 